
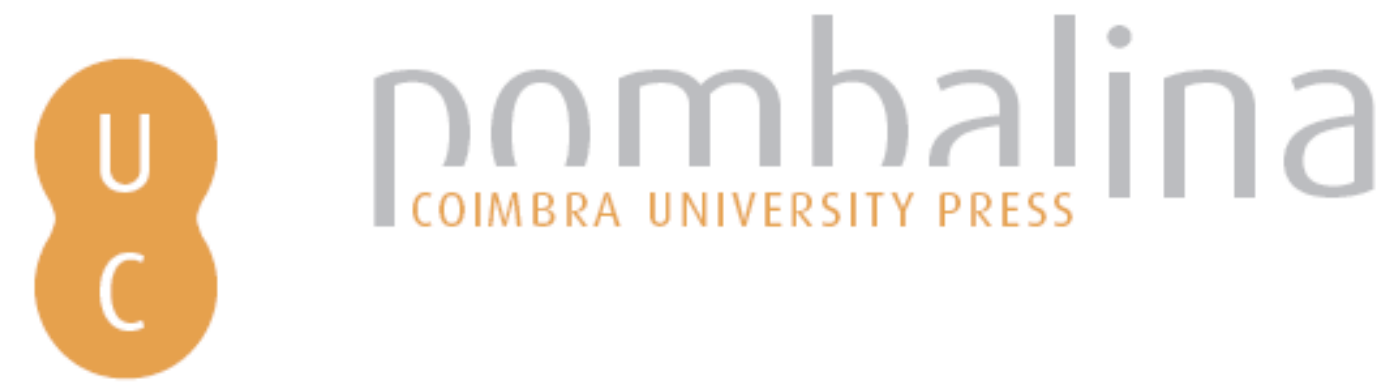

\title{
La función social de la risa y de la comedia: huellas aristotélicas en los tratados de poética de los siglos XVI-XVII
}

\author{
Autor(es): $\quad$ Zoppi, Federica \\ Publicado por: Imprensa da Universidade de Coimbra \\ URL \\ persistente: URI:http://hdl.handle.net/10316.2/44013 \\ DOI: $\quad$ DOI:https://doi.org/10.14195/978-989-26-1550-9_11 \\ Accessed : $\quad$ 26-Apr-2023 12:49:56
}

A navegação consulta e descarregamento dos títulos inseridos nas Bibliotecas Digitais UC Digitalis, UC Pombalina e UC Impactum, pressupõem a aceitação plena e sem reservas dos Termos e Condições de Uso destas Bibliotecas Digitais, disponíveis em https://digitalis.uc.pt/pt-pt/termos.

Conforme exposto nos referidos Termos e Condições de Uso, o descarregamento de títulos de acesso restrito requer uma licença válida de autorização devendo o utilizador aceder ao(s) documento(s) a partir de um endereço de IP da instituição detentora da supramencionada licença.

Ao utilizador é apenas permitido o descarregamento para uso pessoal, pelo que o emprego do(s) título(s) descarregado(s) para outro fim, designadamente comercial, carece de autorização do respetivo autor ou editor da obra.

Na medida em que todas as obras da UC Digitalis se encontram protegidas pelo Código do Direito de Autor e Direitos Conexos e demais legislação aplicável, toda a cópia, parcial ou total, deste documento, nos casos em que é legalmente admitida, deverá conter ou fazer-se acompanhar por este aviso.

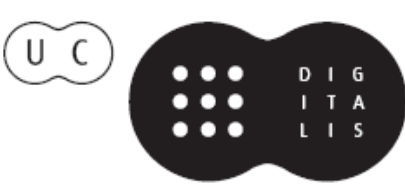




\section{Desplazamientos de la tradición clásica en las culturas hispánicas}

Paola Bellomi, Claudio Castro Filho, Elisa Sartor (eds.)

IMPRENSA DA UNIVERSIDADE DE COIMBRA 


\title{
LA FUNCIÓN SOCIAL DE LA RISA Y DE LA COMEDIA: HUELLAS ARISTOTÉLICAS EN LOS TRATADOS DE POÉTICA DE LOS SIGLOS XVI-XVII
}

(The social function of laughter and comedy: Aristotelian footprints in the poetic treatises of the $16^{\text {th }}$ and $17^{\text {th }}$ centuries)

\author{
Federica Zoppi
}

Università degli Studi di Verona (Orcid: 0000-0003-2335-9430)

Resumen: Este estudio se dedica a analizar el valor social y ético de la comedia -y de la risa que de ella brota - según le atribuyen los tratados de poética de los siglos XVI y XVII. A partir del planteamiento aristotélico de la cuestión, la risa de origen literario se asocia de forma prioritaria con la comedia, como vuelve a proponerse por los tratadistas renacentistas que reflexionan sobre la comedia siguiendo las huellas del Estagirita. Se examinan en particular la Philosophia antigua poética (1596) del Pinciano, el Cisne de Apolo (1602) de Carvallo, el Arte nuevo de hacer comedias en este tiempo (1609) de Lope de Vega, las Tablas poéticas (1617) y Cartas filológicas (1634) de Cascales. La comedia se presenta, ya en la breve reflexión de Aristóteles en la Poética, como un género profundamente arraigado en la sociedad civil, de la cual se consideraba una forma de retrato, proponiéndose como imitación de la vida y de las costumbres civiles. Por eso era necesario ajustar el poder transgresivo de la risa al contexto social para otorgarle un objetivo ético-moral, eliminando su vertiente amenazadora, susceptible de destabilizar la sociedad. La catarsis que la comedia provoca en el espectador teatral tiene precisamente la función de evitar el riesgo de una reacción incontrolada, "domesticando" el impulso transgresivo de la risa con un valor moral de ejemplaridad, que encaja en la concepción renacentista del arte que enseña deleitando.

Palabras clave: Aristóteles, risa, sociedad, tratados poéticos, Siglos de Oro.

Aвstract: This essay studies the social and ethical value of comedy - and the laughter that sprouts from it - as a matter to which was given great consideration in the poetic treatises of the sixteenth and seventeenth centuries. In literature, laughter has always been associated with comedy, starting from the Aristotelian approach to the question; Renaissance treatises on poetic theories usually follow this point of view. This study examines in particular Pbilosophia antigua poética (1596) by Pinciano, Cisne de Apolo (1602) by Carvallo, Arte nuevo de hacer comedias en este tiempo (1609) by Lope de Vega, Tablas poéticas (1617) and Cartas filológicas (1634) by Cascales. In Aristotle's Poetics, comedy is presented as a genre deeply rooted in civil society; it represents a form of portraiture, an imitation of civil life and customs. Therefore, it was necessary to adjust the transgressive power of laughter to the social context in order to grant it an ethical and moral purpose, neutralising its threatening side, which could be considered destabilising to society. The cathartic effect aroused by comedy in the theatre spectator has precisely the purpose of avoiding the risk of an uncontrolled 
reaction, "domesticating" the transgressive impulse of laughter through the moral value of exemplarity; this fits the Renaissance conception of an art which is meant to serve people and delight them.

KeYwords: Aristotle, laughter, society, poetic treatises, Golden Age.

La comedia es uno de los temas centrales de varios tratados compuestos en España e Italia entre los siglos XVI-XVII, que siguen las huellas del planteamiento propuesto por Aristóteles en la Poética, estudiándolo y conformándolo a la nueva época. El redescubrimiento de la Poética fue uno de los motores que impulsaron el desarrollo del género teatral y la definición de su código compositivo: la Poética se acepta tradicionalmente como texto normativo, que establece el canon de la escritura y de la representación dramáticas.

En su obra el Estagirita remitió la disertación sobre la comedia a un segundo tomo, que, sin embargo, o no se escribió o se perdió; los teóricos y comentaristas que se enfrentan a la cuestión manifiestan una tentativa de ir más allá de los preceptos aristotélicos, intentando completar hipotéticamente su teoría ${ }^{1}$. En particular, la cuestión de la utilidad moral del arte es eje central de la reflexión renacentista y la mayoría de los tratadistas se dedicó a ella en un ambiente de productivo debate cultural: las numerosas obras teóricas desarrollaron un interesante diálogo entre tradición e innovación, con el objetivo de adecuar los antiguos preceptos literarios a las nuevas exigencias debidas a la evolución de las costumbres y de la moral (Villari 2002: $\mathrm{x}$ ).

La distinción aristotélica entre tragedia y comedia parece ser el punto de partida imprescindible para toda disertación teórica sucesiva, a partir de la cual la comedia se consideró fuente principal de la risa de origen literario:

La comedia es [...] imitación de hombres peores, pero no respecto a todo tipo de maldad, sino que lo risible es una parte de lo feo. Pues lo risible es un defecto, una fealdad que no comporta dolor ni destrucción, como, sin ir más lejos, la máscara cómica es algo feo y deforme pero sin dolor. (Poética ${ }^{2}, 1449 \mathrm{a}$ 5, pp. 42-43)

La comedia no representa el vicio como corrupción moral, sino más bien los vicios de la gente común, los defectos y las carencias que se manifiestan normalmente en la vida cotidiana, que son causa de reprobación, incluso de risa, pero no de auténtico horror; por eso sus personajes nunca serán "peores" desde

\footnotetext{
${ }^{1}$ Sobre esta tendencia véase Vega 1997: 15-37. La reconstrucción de la teoría incompleta y supuestamente perdida del Estagirita se colocaría, en este sentido, en el mismo origen del neoaristotelismo literario.

${ }^{2}$ A cada tratado citado se atribuye una abreviatura bajo la cual figura en la bibliografía final.
} 
el punto de vista moral ${ }^{3}$.

Esta noción de comedia se vuelve a proponer en los tratados del siglo XVI, donde se establece un vínculo explícito y directo entre comicidad y comedia, que designa el teatro como el lugar privilegiado de la risa de origen artístico. Las estructuras que están en la base de la comedia se identifican como típicas de la comicidad, en particular la burla, que se vuelve a encontrar también como núcleo de la escritura cómica en prosa. En la mayoría de los casos, los tratadistas que se ocupan, más o menos directamente, de lo cómico reducen la reflexión puramente teórica para servirse de ejemplos concretos, presentando una rica casuística de situaciones, normalmente sacadas de burlas teatrales ${ }^{4}$; de esta forma se ofrecen varios modelos prototípicos de comicidad, sin adentrarse en los mecanismos profundos de cómo funciona el artificio cómico. La sustancial imposibilidad de captar la esencia de lo cómico bajo un punto de vista teórico-descriptivo se soluciona y compensa a través de una larga enumeración de ejemplos concretos sobre lo que es cómico. Basta recordar la afirmación tautológica del Pinciano, "la risa es risa" y afirmaciones inciertas e indefinidas como "la risa está fundada en un no sé que de torpe y feo" (Phil. Ant. Poét., Ep. IX, p. 389).

La tratadistica española del Siglo de Oro se desarrolla entre dos tensiones opuestas, como notó Menéndez Pelayo (1974 I: 683-684): hay una tendencia clasicista, que se fundaba en los preceptos de Aristóteles y Horacio, comentándolos en latín o en vulgar, o interpretando sus teorías para la formulación de nuevos tratados originales según un enfoque más moderno, con vistas a ajustar los antiguos preceptos estéticos al canon renacentista; la segunda corriente se centraría en la defensa y desarrollo de las innovaciones propuestas en los dos grandes ámbitos de la literatura española que sufren los cambios más profundos: la poesía, gracias a la obra de Garcilaso de la Vega, y el teatro, por el impulso de Lope de Vega. Las obras que pertenecen a la primera categoría deben mucho a los teóricos italianos que se dedicaron a la reflexión estético-literaria; se puede suponer que muchos intelectuales españoles conocieran la Poética a través de los comentarios y las traducciones latinas o italianas, puesto que las traducciones de la obra de Artistóteles a la lengua castellana se realizan en época más tardía 5 .

${ }^{3}$ Merece la pena mencionar la interesante perspectiva de Alessando Piccolomini, en Annotationi nel libro della Poetica d'Aristotele (1575), según el cual el aspecto "peyorativo" de la comedia no se hallaría en la sustancia de su asunto, sino en la misma acción que lo desarrolla, ya que, para suscitar la risa del auditorio, se hace hincapié en los aspectos ridículos y bajos de los personajes: la imitación estético-literaria se hace, entonces, peor que el modelo de la que procede y que imita: "i vecchi più avari, i giovani più dissoluti, i servi più infedeli, le meretrici più ingannatrici di quello, ch'ordinariamente trovar si sogliono; e il simil discorrendo per le altre sue persone" (Annotationi, f. 51).

${ }^{4}$ Merece la pena precisar que algunos tratadistas italianos, por ejemplo Minturno y Trissino, adoptan una perspectiva más amplia, considerando como modelos de situaciones cómicas también episodios procedentes de la narrativa breve de Boccaccio.

${ }^{5}$ La primera traducción de la Poética al latino fue realizada por Lorenzo Valla en 1498, 
Entre los estudios más significativos que reelaboran los preceptos artistotélicos destaca el tratado en forma dialógica de López Pinciano, Philosophía antigua poética (1596). La epístola IX de la obra se dedica en su entereza a la comedia y, consecuentemente, al tema de la comicidad como su rasgo intrínseco. En primer lugar, se subraya la raíz popular de la comedia, que procedería del término griego "como", que corresponde al castellano "barrio", ya que:

sus autores andaban de barrio en barrio, tomando las figuras que se les antojaba y haciendo personas y condiciones de aquellos cuyas figuras se vestían, pintando al hombre vano, hablador, lisonjero, glotón y a los demás viciosos, según lo eran y aun algo más feamente, porque la comedia es imitación de peores que ellos eran, como dijimos de la tragedia que lo era de mejores. (Phil. Ant. Poét., Ep. IX, p. 380)

Los tratadistas de la época áurea nunca olvidaron la lección de Aristóteles y su descripción de la comedia como representación de los peores, que se contrapone a la tragedia, en la que en cambio se realiza la representación de los mejores ${ }^{7}$. Como en la perspectiva aristotélica, estos "peores" no hacen reír por ser malvados, sino por ser tontos y físicamente feos, es decir, víctimas de una deformidad, exterior o interior. Condición indispensable para que se consiga causar la risa es que estas fealdades sean, sustancialmente, inocuas y no afecten la esfera de lo moral. A este propósito, es interesante la afirmación expuesta por Giason Denores en su Discorso (1586) sobre comedia y tragedia, donde se defiende la función ética y moral de la poesía: puesto que la comedia tiene que educar a los espectadores a la mejor forma de vida popular, se representará, por general, el universo privado y personal, lejos de los palacios y de las dinámicas del poder, que siguen siendo de competencia exclusiva de la tragedia. Es lo que teorizaba también Piccolomini en 1575, al afirmar que la acción de la comedia se funda "in persone di civile, e mediocre stato; e fondate (insomma) in questa

seguida por la de Alessandro de' Pazzi, publicada en 1536. La primera traducción al italiano fue la de Bernardo Segni, de 1549, mientras el primer comentario a la obra fue el de Robortello (In librum Aristotelis de arte poetica explicationes), que remite al año 1548. El De ridiculis (1550) de Vincenzo Maggi, apéndice a su comentario a la Poética, representó una continuación y una respuesta a la obra de Robortello, y ambos se configuran como dos etapas fundamentales en el desarrollo del neoaristotelismo que intentó reconstruir las omisiones de la teoría literaria de Aristóteles. Por lo que atañe al español, las primeras traducciones a la lengua castellana fueron las de Vicente Mariner y Alonso Ordóñez, ambas de 1626, pero solo la segunda parece proceder directamente del griego. Véase Menéndez Pelayo 1974 I: 685-686 y Sánchez Laílla 2000: 15.

${ }^{6} \mathrm{E} 1$ mismo origen filológico del término lo plantea asimismo Carvallo en el Cisne de Apolo (III, p. 257); esta hipótesis se encuentra ya en las palabras de Aristóteles (Poética, 1448a 3, p. 39).

7 "En esto consiste también la diferencia que separa la tragedia de la comedia. Pues ésta tiende a imitar a personas peores que las reales, y aquélla a personas mejores" (Poética, 1448a 2, p. 38). 
vita comune, che tutto il giorno si tratta, e si maneggia” (Annotationi, f. 142).

El espíritu ligero de la comedia no otorga a los autores la posibilidad de descuidar los preceptos generales que están en la base del arte humanístico-renacentista: a través de la risa, la comedia debe enseñar y proporcionar ejemplos de prudencia que se puedan aplicar a la vida cotidiana, social y familiar. El problema de la moralidad del arte, que es eje central de la estética de la época, domina en la definición de los límites de la comicidad: esta se inserta en la poética clasicista del "enseñar deleitando", desempeñando un papel social y moral que se mantiene a una constante distancia de seguridad de las transgresiones más irreverentes. El hombre es un "ser social responsable que puede mejorar o empeorar por efecto de la literatura” (Bobes Naves 2008: 381), la que se configura, de esta forma, como un instrumento de enseñanza ética.

No es casual que el mismo Pinciano subraye que se promulgaron "leyes justas" (Phil. Ant. Poét., Ep. IX, p. 380) para moderar las comedias y evitar que la imitación se hiciese demasiado "personalizada", mencionando los nombres de las personas a las que se hacía referencia. A partir de estos ataques personales directos se desarrolla, según el autor, la sátira, forma expresiva que elude maliciosamente estas leyes civiles ${ }^{8}$. Al contrario, el papel social de la comedia era, según las palabras de Piccolomini, que "mordesse, e riprendesse, non gravemente, ma con qualche discreta modestia, e più tosto ridicolosamente, che ingiuriosamente" (Annotationi, f. 94) ${ }^{9}$. Se evidencia, de esta forma, la conciencia del poder desacralizador de la palabra cómica, que puede representar un peligro concreto en el ámbito social cuando se interprete como un arma contra alguien. Al contrario, en la comedia la percepción de esta amenaza social se contrasta a través de un proceso de "generalización", vale decir presentando figuras ejemplares que representan vicios sin ponerles nombre alguno. La ejemplaridad es el vehículo de la enseñanza, necesaria para que la comedia sea socialmente útil, elevando los personajes a papeles funcionales y a símbolos universales.

La breve discusión del Pinciano (Phil. Ant. Poét., Ep. IX, p. 381) sobre la

${ }^{8}$ Minturno, autor de un comentario a la obra de Aristóteles publicado en 1564, considera propia de la comedia la materia escénica mediana y común, "de personas que viven en el campo, o en la ciudad, que se dedican al cultivo de la tierra, o están a sueldo, al comercio, o a otros empeños semejantes", mientras que la sátira representa a "los humildes y bajos, los risibles y personas muy a propósito para hacer reír" (Arte poética, p. 283).

${ }^{9}$ Refini 2009: 98 ss. realizó un interesante estudio que analiza el tratado de Piccolomini en relación con la obra aristotélica, comparándolo a los de Maggi (In Aristotelis librum de Poetica communes explanationes) y Castelvetro (Poetica d'Aristotele volgarizzata et sposta). Maggi y Castelvetro se colocarían, en la teoría del estudioso, en los polos opuestos del binomio prodesse et delectare: Maggi interpreta a Aristóteles bajo una perspectiva moralista y pedagógica, evidenciando el valor moral que confirió a la poesía; según Castelvetro, al contrario, el fin principal de la poesía teorizado por Aristóteles sería el de entretener y, solo de forma secundaria, enseñar. El punto de vista de Piccolomini se configura como una posición mediana definida como "edonismo etico" (Refini, 2009: 98) que les otorga a ambos polos la misma importancia: la poesía puede transmitir con éxito un mensaje útil solo si consigue también entretener al receptor, captando su atención. 
comedia llega a tres conclusiones principales:

Comedia es fábula que, enseñando afectos particulares, manifiesta lo útil y dañoso a la vida humana.

La comedia es poema activo negocioso, cuyo estilo es popular y fin alegre.

Comedia es imitación activa hecha para limpiar el ánimo de las pasiones por medio del deleite y risa.

La comedia suscita en el espectador una forma de catarsis equivalente a la catarsis trágica ${ }^{10}$, aunque de polo opuesto. La tragedia, según el Pinciano, limpia el alma de las pasiones "por medio de miedo y misericordia" (Phil. Ant. Poét., Ep. VIII, p. 335); a través de esta misma forma cumple con su objetivo de enseñar, mientras que la comedia lo alcanza por medio de "pasatiempo y risa" (Phil. Ant. Poét., Ep. IX, p. 388). Se reitera el poder "activo" de la comedia, como algo que "actúa", es decir que produce un resultado y que "tiene eficacia, poder y virtud para obrar" (Aut.), característica subrayada también en el Cisne de Apolo (1602) de Carvallo a la hora de definir la poesía dramática (Cisne, III, p. 254). Francisco Cascales en su tratado vuelve a proponer el mismo binomio: "la comedia es imitación dramática de una entera y justa acción humilde y suave que por medio del pasatiempo y risa limpia el alma de los vicios" (Tablas, f. 351). Ambas representaciones dramáticas llevan a una catarsis que, en la tragedia, se realiza en forma de purgación de sentimientos como la misericordia y el terror, mientras que la comedia "limpia" los ánimos de aquellos sentimientos que turban la vida cotidiana con pequeños problemas y preocupaciones concretas ${ }^{11}$. Me parece que se puede afirmar que una de las mayores aportaciones del neoaristotelismo de la época áurea a la hora de tratar de completar la filosofía del Estagirita fue precisamente la propuesta de la existencia de una catarsis cómica paralela a la trágica, que eleva el género cómico atribuyéndole la misma función educativa desempeñada por la tragedia; en este sentido el binomio compasión/temor - $\mathrm{O}$ misericordia/miedo-, a través del cual se lleva a cabo la catarsis trágica, tiene su equivalente, análogo y opuesto, en la combinación de pasatiempo/risa, necesaria para la catarsis cómica.

Los interlocutores del diálogo del Pinciano aceptan, entonces, la tercera

${ }^{10}$ Aristóteles subrayó la función catártica de la tragedia como un proceso de purificación emocional que posibilitaba el acceso a un estado de trascendencia de las pasiones para alcanzar una conciencia superior y una pacificación interior. Se diferencia de la noción de catarsis platónica, que tiene una función cognoscitiva, de liberación de las restricciones para conseguir la verdad a través de una purificación intelectual; según la teoría platónica la catarsis sería fruto de las relaciones dialógicas socráticas, y no de la fruición artística, ya que la poesía trágica, al representar un alejamiento de la verdad, no puede proporcionar un medio para conseguir un estado de conocimiento auténtico.

${ }^{11}$ Véase también Minturno sobre la función conmovedora de la tragedia, que "purga" deleitosamente pasiones como piedad, terror, maravilla de los ánimos de los espectadores (Arte poética, pp. 305 y ss.). 
definición como la más apropiada y completa; luego discuten las diferencias principales entre comedia y tragedia. La comedia, aunque comparta algunos elementos con la tragedia, los escenifica para llegar a suscitar emociones completamente diferentes: por ejemplo, el horror y la compasión suscitados por la tragedia no penetran el auditorio de la comedia:

Y la diferencia que hay de los temores trágicos a los cómicos es que aquéstos se quedan en los mismos actores y representantes solos y aquéllos pasan de los representantes en los oyentes. (Phil. Ant. Poét., Ep. IX, p. 385)

Además, la tragedia representa la vida de la que hay que huir, mientras que la comedia reproduce la que se debería tratar de realizar; el núcleo de la tragedia es la historia, por el contrario, la comedia es toda "fábula"; finalmente, la tragedia exige un estilo alto y la comedia uno bajo, que se conforma a sus personajes y situaciones humildes y populares. Cada una de estas características inspira una reflexión más pormenorizada, con la que se llega a concluir que todas las diferencias detectadas no son ciertas ni absolutamente invariables. En particular, la comedia, que se constituye de "carácteres" y "tipos", parece acercarse en varios aspectos al género de tragedia que el Pinciano define "morata", que tiene una explícita función didáctica: "morata se dice la que contiene y enseña costumbres" (Phil. Ant. Poét., Ep. VIII, p. 339). A diferencia de la tragedia denominada "patética", la "morata" se apunta a un objetivo más moral que estético, al igual que la comedia, así que su acción trágica se describe también como "mezclada de cómica” (Phil. Ant. Poét., Ep. VIII, p. 340). Proporciona ejemplos concretos de comportamiento, haciéndose vehículo ideal de la combinación horaciana de deleite y provecho, y admite también un final feliz. Por todas estas razones, la morata se considera más útil, a pesar de que no conlleve el mismo deleite trágico que la tragedia definida "patética", la cual, en cambio, cumple con el objetivo primario de mover a conmiseración. Cascales, en sus Tablas poéticas (1617), extendió esta definición a la comedia en general, clasificando su enredo precisamente como "fábula morata" (Tablas, f. 371) - es decir ética- en la que típicamente se representan las costumbres, como ocurre en la comedia, "espejo de la vida humana" (Tablas, f. 385).

En sustancia "el género trágico se divide en dos categorías, la que expresa la emoción auténticamente trágica y la que da una lección moral” (Shepard 1970: 92). La caracterización de los personajes típica de la comedia parece poderse trasladar también al teatro más "grave", en un movimiento que, según la opinión de Shepard (1970: 96), se debe al afán renacentista de realizar un arte didáctico. El único elemento, en la teoría escénica del Pinciano, que separa siempre claramente tragedia y comedia es que solo la comedia se constituye alrededor de lo ridículo como fuente de risa, factor que, de todas formas, siempre 
se emplea como medio para transmitir una enseñanza al público popular ${ }^{12}$, ya que la risa es impulso típico de la gente común y simple, mientras que es cosa insólita para las personas "graves".

Carvallo, en el Cisne de Apolo, se ocupó de la comedia describiéndola como "imitación de la vida, espejo de costumbres, imagen de verdad" (Cisne, III, p. 256), cuyo asunto se centra en "fábulas y ficciones, semejantes a verdad" (Cisne, III, p. 258). A la objeción que el propósito de la comedia sería la pura diversión, de la que gozar en los momentos de ocio, se contesta que el entretenimiento fruto de la comedia es absolutamente honesto, acorde con las leyes divinas y humanas, legítimo y deseable como forma de alivio del trabajo cotidiano, al que se volverá con más eficacia y productividad después haberse concedido un descanso ${ }^{13}$. La comedia no es solo una representación de la sociedad - "espejo de todas las edades, de todas las costumbres, de todas las nociones y todos los estados [...] cifra y mapa de la fortuna, ansí de la persona particular como de toda la república" (Cisne, III, p. 265)—, sino desempeña también una precisa función social, la de procurar al individuo una oportunidad de distracción y desahogo del cansancio causado por el trabajo, después de la cual, es posible volver a desempeñar el propio papel social y productivo en el marco de la colectividad. Ya Aristóteles en la Ética (IV, 1128a-1128b, pp. 234-235) atribuía a la risa dignidad y valor social, además de un propósito estético. Para que esto se realice plenamente es necesario un espíritu sabio y templado, que sepa captar el entretenimiento sin llegar al exceso; se trata de la inclinación típica del hombre agudo e ingenioso, que se denomina eutrapelia, es decir, la capacidad de divertirse con moderación y dignidad, sin dejarse llevar por excesos indecorosos. De la risa es posible sacar provecho e, incluso, mejorarse, adquiriendo una aptitud más abierta al bien (eutropia) y más disponible y benigna hacia los demás en las relaciones sociales (eunoia) ${ }^{14}$.

En las Tablas poéticas de Cascales se puede detectar la influencia del Pinciano y de Carvallo, pero también de los tratadistas italianos, en particular

${ }^{12}$ Sobre este papel de la comedia, que "se sirve" del poder del entretenimiento para llegar al objetivo del prodesse, véase también Nardi 2006: 39 y ss.

13 "Llámasla entretenimiento y, siendo tan lícito y honesto, permitido es por leyes divinas y humanas para descanso de los hombres, que no pueden estar siempre intentos al trabajo; y no se pierde el tiempo que en descansar se gasta, pues se vuelve con mayores alientos al trabajo" (Cisne, III, p. 264).

${ }^{14}$ Exceder los límites de lo ridículo significa convertirse en un bufón; al contrario, los que no admiten ni captan el humorismo se consideran demasiado duros y rústicos. Los pasajes de la obra aristotélica que tratan este asunto parecen configurarse como una respuesta a Platón que, en la República, presenta la comedia como una posible amenaza a la vida común y pacífica, porque causa de desorden. Plebe 1952: 24 resumió la diferencia entre los dos filósofos afirmando que "per Platone il comico può essere valutato solo come l'opposto del serio. Per Aristotele invece il comico si avvia ad essere l'espressione e l'imitazione della vita comune". 
Minturno y Robortello ${ }^{15}$. La cuarta tabla está dedicada a la comedia, que se reconoce inmediatamente como el género más frecuentado por parte de los poetas españoles. Otra vez, se vuelve a encontrar la comedia que, en calidad de momento recreativo, produce una forma de catarsis precisamente gracias al desahogo cómico, que se traduce en el acto físico de la risa, "maliciosa, aguda, ingeniosa, fundada en la fealdad, y torpeza agena” (Tablas, f. 388). Como afirmó Aristóteles, se separa el espacio de la comedia del de la tragedia por no incluir nada realmente doloroso. Si lo ridículo se origina en lo feo, entonces, hay que limitar la gravedad de las causas para que el público no reaccione con compasión y empatía, sino con una risa divertida ${ }^{16}$.

Cascales amplía esta definición en otra obra posterior, las Cartas filológicas (1634):

tenemos en el teatro poesías que nos descubren las rayas de la naturaleza humana, y nos avisan del mal y del buen suceso que nos aguarda, y nos traen a la memoria los varios acontecimientos de la vida, y de ellos nos hacen un mapa universal, donde cada uno conoce y ve como en espejo sus costumbres, por las del otro que allí se representa, y aprende aquello que le ha de ser de provecho, y abomina aquello que le ha, de ser dañoso y veneno mortal si lo toma y sigue. (Cartas, Déc. II, Ep. III)

Cascales niega con decisión la existencia de la tragicomedia ${ }^{17}$ : tragedia y comedia seleccionan asuntos diferentes y tienen, intrínsecamente, fines opuestos que nunca se podrán conciliar armónicamente en una fábula que mezcle los rasgos cómicos con los trágicos: "el trágico mueve a terror, y misericordia: el cómico mueve a risa". Las obras que intentan llevar a cabo esta fusión antinatural "son hechas contra razón, contra naturaleza, y contra el arte" (Tablas, ff. 372-373) y si Plauto llamó su Anfitrión "tragicomedia" solo fue por burla ${ }^{18}$. Cascales fue bastante crítico contra el teatro contemporáneo, quedándose en la obstinada defensa de un riguroso $-\mathrm{y}$ ya anacronístico- preceptismo clásico:

${ }^{15}$ Vega 1997: 80-81 subraya la influencia que las obras de Robortello y Maggi ejercieron en la tratadistica posterior, italiana y española.

16 Véase también las palabras de Castelvetro que, en 1570, presentaba esta teoría aristotélica de forma análoga: "Anchora quelli inganni che nascondo dalle "nsidie degli huomini studiosamente tese fanno ridere purche allo "ngannato non segua grave danno" (Poetica d'Aristotele, f. 53v).

${ }^{17}$ Otros tratadistas, en cambio, admiten esta posibilidad; Denores, por ejemplo, acepta la existencia en el mismo enredo de dos fábulas opuestas que, sin embargo, parecen mantenerse por separado: la fábula cómica está protagonizada por personajes populares y tiene un desenlace feliz, mientras que la fábula trágica implica figuras nobles e ilustres y termina en la desventura.

${ }^{18}$ También el Pinciano menciona esta obra plautina afirmando que es una de las que "no son puras comedias y que tienen olor de lo trágico" (Phil. Ant. Poét., Ep. IX, p. 383), donde se evitan burlas y situaciones demasiado ridículas para guardar el decoro de los personajes graves. 
no aceptó ciertas transgresiones técnicas, como la falta de unidad temporal y la mezcla de elementos cómicos y trágicos, que llevaría a un resultado innatural y monstruoso $^{19}$. A pesar de esto, se admite la posibilidad de una comedia definida “doble" (Tablas, f. 332), con personajes nobles al lado de personajes humildes; de la misma forma, existe la tragedia "doble" ${ }^{20}$, que tiene enredo trágico con desenlace feliz ${ }^{21}$.

Con estas afirmaciones Cascales parece disentir radicalmente de la teoría que Lope de Vega había expuesto hacía pocos años, en 1609, en el breve tratado poético, Arte nuevo de hacer comedias en este tiempo 22 : la unión de cómico y trágico se presenta como el eje central de su disertación sobre el nuevo teatro contemporáneo $^{23}$, que admite esta trangresión hasta convertirla en norma deseable:
Mas pues del arte vamos tan remotos y en España le hacemos mil agravios, cierren los doctos esta vez los labios.
Lo trágico y lo cómico mezclado, y Terencio con Séneca, aunque sea como otro Minotauro de Pasife, harán grave una parte, otra ridícula, que aquesta variedad deleita mucho; buen ejemplo nos da naturaleza que por tal variedad tiene belleza. (Arte nuevo, vv. 171-180, pp. 312-313)

Según Lope, no es el asunto que selecciona el estilo trágico o cómico; no existe, efectivamente, una materia intrínsecamente trágica que se oponga a una cómica; antes bien, todo se puede moldear según las intenciones autoriales. Cascales, en cambio, formuló una clasificación más definida: lo trágico procede de la

${ }^{19}$ Cervantes parece haber compartido muchas de estas críticas (véase en particular el capítulo I, 48 del Don Quijote), al igual que otros autores, entre los cuales Andrés Rey de Artieda, Esteban Manuel de Villegas, Cristóbal de Mesa, Cristóbal Suárez de Figueroa, Antonio López de Vega, que objetaron precisamente contra la confusión entre lo cómico y lo trágico, la risa y el llanto, entre lo popular y lo noble.

${ }^{20}$ Con el término "doble" Minturno define "aquella fábula que sea mixta de poesía cómica y trágica” (Arte poética, p. 403).

${ }^{21}$ Según el análisis de Menéndez Pelayo 1974 I: 724, Cascales no entendió a fondo el teatro de su tiempo a causa de una excesiva dependencia de los modelos clásicos, en particular parece interpretar a Terencio como norma absoluta, excluyendo del universo de la comedia elementos, como las doncellas solteras o los viejos casados, que existen en otros autores clásicos, como Plauto, el cual representa un mundo más amplio y abigarrado que el llevado a la escena por Terencio.

22 Sobre la relación del Arte nuevo con sus fuentes clásicas y sus antecedentes italianos véase Conde Parrado 2010 y Profeti 2010.

${ }^{23}$ Sobre este asunto en el teatro de Lope y las modalidades aplicadas por el autor para alcanzar esta hibridación de cómico y trágico véase Antonucci 2011. 
política, de la administración del gobierno y del estado, mientras que lo cómico viene de la economía, en particular de cuestiones menores que atañen al balance familiar; además, el género satírico se origina en la ética, reprobando los vicios e intentando guiar hacia el mejor comportamiento social posible (Tablas, f. 25).

Algunos de los temas del tratado de Lope fueron adelantados por Giraldi Cinthio unos cincuentas años antes: su poética parece fundarse en un ideal de moderación aparentemente clásico — "la bellezza, adunque, è posta nel mezzo fra due estremi" (Intorno al comporre, p. 209) - que, en realidad, pone en duda algunas de las afirmaciones teóricas antiguas. En la general $-\mathrm{y}$ tradicionalintención de evitar los excesos, tanto de vulgaridad en la comedia, como de patetismo en la tragedia, los dos géneros acaban acercándose, matizando los rígidos límites que clásicamente dividían la expresión trágica de la cómica ${ }^{24}$.

Lope, como sus predecesores, presenta la comedia como imitación de las acciones y de las costumbres y prescribe unos preceptos técnicos que, en realidad, poco tenían de efectivamente innovador y seguían, en la mayoría de los casos, a Aristóteles en la aplicación de la unidad de acción, de un estilo elegante y de un verso conforme con la materia tratada, buscando un efecto general de decoro. Lo que, en cambio, parece renovador, e incluso revolucionario, es el papel que se le otorga al público: si ya son escasos los teóricos que, a la hora de determinar el objetivo del arte, consideraron también la inclinación del receptor, la posición de Lope da un paso más allá, dando prioridad al gusto del público sobre cualquier precepto, haciendo del arte dramático una manifestación literaria que, en su misma composición, tiene que ajustarse a las expectivas y exigencias del público al que se dirige y que la financia ${ }^{25}$. Lope reconoce, contra el rigor de las normas tradicionales, que la preceptiva dramática aplicada por la mayoría de los autores del Siglo de Oro no era la que sabía entretener al público, ni suscitaba su atención. De esta manera el teatro se hace también comercio, actividad económica de la que sacar un provecho concreto, trabajo del que vivir y que, por eso, tiene

${ }^{24}$ Aristóteles mantenía lo cómico y lo trágico claramente separados, también en las características técnicas: la simultaneidad de múltiples enredos se consideraba rasgo aceptable en la comedia, pero no en la tragedia, que apuntaba necesariamente a una acción única. Además, mientras que Giraldi Cinthio, como ya Denores, admite la posibilidad de una fusión entre cómico y trágico, para que la tragedia pueda resolverse en un desenlace feliz, Aristóteles, en cambio, prescribía la trayectoria opuesta, es decir, de la felicidad a la infelicidad. A pesar de esto, Giraldi Cinthio construyó su actividad de autor dramático en el respeto de las normas aristotélicas, en particular en la tragedia titulada Orbecche.

${ }^{25}$ Mas ninguno de todos llamar puedo / más bárbaro que yo, pues contra el arte / me atrevo a dar preceptos, y me dejo / llevar de la vulgar corriente adonde / me llamen ignorante Italia y Francia / Pero ¿qué puedo hacer si tengo escritas, / con una que ha acabado esta semana, / cuatrocientas y ochenta y tres comedias? / Porque, fuera de seis, las demás todas / pecaron contra el arte gravemente. / Sustento, en fin, lo que escribí y conozco / que, aunque fueran mejor de otra manera, / no tuvieran el gusto que han tenido / porque a veces lo que es contra lo justo / por la misma razón deleita el gusto. (Arte nuevo, vv. 362-374, pp. 335-336) 
que seducir a aquel auditorio sin el cual ni siquiera podría existir. El aspecto más innovador de Lope es precisamente el hecho de conciliar una perspectiva tradicionalista con las nuevas exigencias de la sociedad de su tiempo.

Lo que emerge de estos tratados y, en particular, de las palabras de Lope, es la conciencia cada vez más determinada del poder del medio teatral y de la influencia que puede ejercer sobre los espectadores: lo que la comedia enseña está destinado a aplicarse a la vida cotidiana y, por lo tanto, sus consecuencias sociales son directas e inmediatas. Esta caracterización de la comedia se puede encontrar también en las palabras de Piccolomini:

Le comiche imitazioni [...] ci rendono cauti, avvertiti, prudenti, e con gli esempi in somma, che ci mostrano delle fraudi, e dei vizi, di che per il più son piene le azioni ordinarie di questa vita nostra comune; ci fan divenir coi casi degli altri, più prudenti nei propri casi nostri. (Annotationi, Proemio, s.n.)

Esta concepción de la fuerza de la comicidad teatral se encuentra ya en la postulación de Minturno en L'arte poetica: la vis comica de la comedia deriva su eficacia de la representación concreta, delante de los ojos de los espectadores, de las situaciones más risibles. El "cómico de obras", entonces, consigue impresionar al receptor de manera más intensa que el "cómico de palabras", puesto que el autor

narrando destaca y pone ante los ojos las cosas verosímiles, y las que son feas talmente como la cara de aquel de quien se habla y el razonar y el vestido se ve directamente; el oyente estima entonces que todo esto se hace en su presencia, y que son verdaderas las cosas narradas. (Arte poética, p.431)

Se trata de una comicidad "de acción", concreta y físicamente representada en la escena. Además, se podría añadir, la comicidad teatral es también corpórea: adquiere una eficacia superior precisamente porque el teatro es el único medio en el cual, a las estrategias literarias, se suma todo lo que los actores y el contexto teatral añaden al texto (mímica, vestidos, gestos, gestualidad, etc.).

La tratadistica de la época, sobre todo por lo que atañe a la comedia, parece, por lo general, orientarse hacia un ennoblecimiento del género cómico, elevándolo a nivel del trágico, justificando, sobre todo bajo un punto de vista moral, una manifestación literaria que en el Renacimiento se estaba haciendo cada vez más popular también en los ambientes cultos. No se podía, entonces, admitir que se tratase de obras que no cumplían con las normas morales, que se suponía gobernasen siempre cada acto de creación artística. Por un lado, hay la necesidad de dar dignidad estética no solo a un género como la comedia ${ }^{26}$, sino más bien a

\footnotetext{
${ }^{26} \mathrm{El}$ mismo Artistóteles en la Poética alude a esta desigualdad a la hora de considerar tra-
} 
una forma de expresión artística que iba conquistando un público cada vez más amplio, también en el ámbito de la prosa con la difusión de la narrativa de entretenimiento. Por otro lado, se mantiene la tendencia aristocrática moralista que impone con superioridad su ideología a las clases más bajas con en el objetivo de educar al vulgo. En este sentido, la aproximación del comentario de Robortello a la cuestión de la moralidad del arte parece ser particularmente innovadora, a pesar de ser una de las aportaciones más tempranas. La atención del autor se centra en el componente artístico de la poesía, separándolo de la cuestión moral. $\mathrm{E}$ l teatro representa pasiones, negativas y positivas, y está protagonizado por personajes buenos o malos, que no tienen otro valor ni otro significado que el escénico. El objetivo del arte es el arte mismo, y los juicios a los que se somete deberían mantenerse en el plano artístico, sin aplicarlos a cuestiones extrínsecas como la moral ${ }^{27}$.

Bobes Naves (2008) identificó en el clima de la Contrarreforma la causa por la que se puso en duda la autonomía del arte, otorgándole una precisa función social; la misma que, por ejemplo, se encuentra en el teatro de Lope de Vega, portavoz de la ideología monárquica y defensor del orden social. La cultura de los Siglos de Oro subraya el valor moral y ético del arte que, ni en sus manifestaciones más ligeras y divertidas, puede permitirse ser frívola. Esto se hará evidente sobre todo en el teatro, como expresión cultural que alcanza de forma directa e inmediata un público muy vasto, convirtiéndose en auténtico instrumento de persuasión.

Aristóteles, destacando la necesidad de que el espectador pudiera sacar de la comedia ejemplos de conductas aplicables, ya parecía subrayar el potencial

gedia y comedia, afirmando que esta última no fue "tomada en serio desde el principio" (Poética, 1449b, p. 43).

${ }_{27}$ Análoga parece ser una aportación menor, pero muy interesante por su modernidad, la de Giulio del Bene, que compuso la lección Che la favola della commedia vuole essere onesta e non contenere mali costumi, leída en 1574 en Italia durante una sesión de la Accademia degli Alterati. $\mathrm{El}$ autor le otorga a la comedia la dignidad de un género que no implica un nivel bajo, ni en lo que concierne la forma ni en el contenido. Cada género constituye su eficacia y encuentra su perfección en el cumplimiento de sus rasgos específicos y de su naturaleza, que, por lo que concierne la comedia, se hallan en la esfera de lo mediano. Del Bene se alineó con la definición tradicional aristotélica de la comedia como imitación de los peores, excluyendo de ella la acepción moral: no se representa la deshonestidad, que nunca puede ser fuente de risas, sino solo de reprobación. Proponiendo los ejemplos de Aristófanes, Plauto y Terencio, Del Bene subrayó como la comedia clásica, griega y latina, no tiene nada de despreciable o indecoroso: "Se io non mi inganno, sì come il fine della tragedia è il più delle volte misero e doloroso e dello artefice di essa è il muovere compassione e timore, così il fine della comedia deve essere allegro e giocondo et il comico debbe muovere in essa il riso et il contento; come sarà egli mai possibile che egli ciò consegua e per la favola disonesta e per quelli che leggeranno la sua commedia, o verso coloro che recitare la udiranno, se con la bruttezza della disonestà egli corromperà e guasterà la sua favola, che tale vizio non riceve, e se gli auditori, in cambio di allegrezza e contento, odio e sdegno e vergogna da leggerla et udirla ne riportono?” (Favola, p. 185). 
peligro social que el teatro podría representar ${ }^{28}$. Efectivamente, el propósito didáctico de la comedia parece dirigirse más a la ética colectiva que a la moral individual. La comedia asume un valor civil y social, al considerar la población como un cuerpo colectivo, proporcionando una representación de la manera en la que vive la gente común como resultado de las decisiones tomadas por parte de las esferas oficiales. La existencia de este universo "mediano", sin embargo, fue detectada también en la tragedia, por ejemplo por parte de Denores:

Le principal persone della tragedia e della comedia [...] deono esser tra buone e cattive, cioè mediocremente buone e mediocremente cattive per qualche errore umano; ma la comedia deve esser delle persone mezzane tra buone e cattive negli errori umani per certe sempietà e sciocchezze che concitano il riso; e la tragedia tra buone e cattive negli errori umani per certe orribilità che concitano il terrore e la misericordia. I mezzani errori degli uomini grandi et illustri sono gravemente castigati dalla divina providenza [...]; et i mediocri commessi per ignoranza dalle persona private non sono così aspramente condennati, rimanendo nascosti e sepolti nella loro bassa fortuna e simplicità, non essendo di tanto cattivo essempio. [...] Le facezie, i motti et i ridicoli, ne' quali è fondata la comedia, non possono aver luogo in quelle persone che sono in tutto buone, essendo cosa empia e contra le creanze civili schernirsi e burlarsi di esse, né parimenti in quelle che sono in tutto cattive e scelerate, meritando esse maggior pena e castigamento di quel che porta seco il ridicolo. (Discorso, pp. 384-385)

Se reduce la diferencia entre los personajes de la comedia y los de la tragedia, que, según la opinión de Denores, parecen apartarse bajo el punto de vista de la procedencia social, pero no moral. En los dos casos, se trata de personae sometidas a la posibilidad de caer en el error, que es, al fin y al cabo, lo que funda la misma acción dramática y que constituía la misma clave de lo cómico aristotélico. El Pinciano parece proporcionar la misma idea, es decir el personaje trágico no tiene que ser ni malo ni bueno, sino más bien "de tal condición que, por algún error haya caído en alguna desventura y miseria especial” (Phil. Ant. Poét., Ep. VIII, p. 340). Si, por una parte, Lope de Vega - y con él Giraldi Cinthioacerca tragedia y comedia hasta proponer una fusión bajo la perspectiva estética y dramática, otros tratadistas, como el Pinciano, anulan la distancia entre los dos géneros desde el punto de vista de la moralidad expresada por sus personajes.

${ }^{28}$ La génesis de esta visión politizada de la comedia tiene sus raíces ya en la República de Platón, donde el término eutrapelia designa un grado moderado y aceptable de ridículo. Sin embargo, este concepto conlleva una sensación de ambigüedad, debida a la naturaleza ilusoria del placer de la risa. Esto, de hecho, no es objetable en sí mismo, pero se convierte en un peligro cuando se identifique con una pérdida de control, con una expresión de lo irracional del alma que puede afectar toda la sociedad. 
De todas formas, la dignidad, tanto estética como moral, del género cómico se compara y se aproxima cada vez más a la que se atribuye tradicionalmente al trágico.

Tragedia y comedia no se diferencian ni en la estructura ni en los objetivos, puesto que las dos comparten el mismo propósito pedagógico, que se realiza a través de un momento de catarsis; las diferencias sustanciales se hallan, como subraya Villari (2002: xxxviii), en la calidad de las acciones representadas y en las estrategias empleadas para suscitar esta catarsis en el público.

Esta misma diferencia se subraya también en la Philosophia antigua poética:

Como la tragedia con lástimas ajenas sacaba lágrimas a los oyentes, las comedias con cosas de pasatiempo sacan entretenimiento y risa; y ansí ésta como aquélla, llorando y riendo, enseña a los hombres prudencia y valor, porque la tragedia con sus compassiones enseña valor para sufrir y la comedia con sus risas prudecia para se gobernar el hombre en su familia. (Phil. Ant. Poét., Ep. IX, p. 381)

Si parece claro el hecho de que la comedia suscita la risa en los espectadores, hay que precisar también, como hizo Giraldi Cinthio, que hace falta evitar situaciones y medios demasiado vulgares o groseros, ya que siempre se trata de una risa que apunta al decoro y a educar la conciencia ético-moral del espectador, siguiendo los ideales de la moderación y la prudencia como lógica de conducta social. El propósito de las burlas escenificadas será, entonces, el de

indurre negli animi loro buoni costumi, perché, venendo tal riso per cosa sconcia da essere col riso beffata, lo spettatore cerca di non incorrere in cosa tale per essere schernito et se forse vi si vede essere incorso, se ne astiene, onde aviene che così purga la comedia gli animi col riso, come gli purga la tragedia col terribile et col compassionevole. (Intorno al comporre, p. 310)

La risa que brota de la comedia, así como el llanto que se origina en la tragedia, no representan los objetivos finales de la obra - "il comico non si metta il riso innanzi et il tragico il pianto per suo fine" (ibidem) - sino medios con los que llamar la atención del público para que se abra a la recepción de una enseñanza. Por eso, la comedia que suscite risa a través de vulgaridad y que no respete el principio estético y ético del decoro no puede considerarse digna ni bien lograda.

Lo cómico plantea el problema de introducirse de forma armónica en el contexto social: el propósito de enseñar tiene que neutralizar las vertientes transgresivas de la comicidad; se proponen modelos que tienen que ser evitados, alcanzando una enseñanza positiva a través de la representación de lo negativo. Todo lo que suscita risa parece originarse a partir de una rebelión contra el orden 
de la cual se hace cómplice el que se ríe, es decir algo que rompe o perturba una entidad lógicamente compuesta, como puede ser una costumbre social, una expresión lingüística, una imagen estética, una convención moral o ética ${ }^{29}$. A través de la risa se exorciza este poder transgresivo, admitiendo lo cómico en las instancias sociales como algo que no representa un peligro sino solo un motor de diversión, algo tolerado e, incluso, utilizado por las clases dominantes para transmitir un mensaje social al pueblo, como ocurre precisamente en la comedia áurea ${ }^{30}$.

En este sentido, condición necesaria por la cual se produzca la risa es la falta de identificación por parte del espectador en el personaje del cual se ríe. Lo expresó con gran claridad Trissino en su Poética (1529) 31 al afirmar que "niun gobbo si ride di un altro gobbo, né zoppo di zoppo" (Divisione, p. 70). También por esta razón, la catarsis generada por la comedia es de polo opuesto con respecto a la suscitada por la tragedia: la comedia supone que el espectador tome las distancias de lo ridículo y lo perciba como algo ajeno que lo afecta directamente; al contrario, la tragedia, para conseguir la purgación de las pasiones, se funda en un sentido de empatía y participación de los sufrimientos padecidos por los personajes ${ }^{32}$. Por una parte, lo cómico desempeña una función denigradora, que ridiculiza un sujeto percebido como extraño, como una amenaza al orden natural o tradicional; por otra parte, el resultado es una "risa de adaptación", que permite incluir estos elementos en el ámbito de lo conocido y de lo que se puede clasificar. La risa siempre se configura como algo ambivalente, que subraya lo negativo para familiarizarse con ello, pero, al mismo tiempo, procede siempre de una posición de superioridad desde la cual se puede juzgar el mundo.

\footnotetext{
${ }^{29}$ Jammes 1980: 6-7, por ejemplo, a la hora de clasificar los casos discutidos en la Philosophía antigua poética que producen un efecto cómico, enumera cinco categorías: lo disparatado, esto es lo cómico de la simpleza y de la necedad expresado por el gracioso o por el bufón, hasta sus manifestaciones más absurdas; lo descompuesto, que se halla en la fealdad y deformidad física y en actos ridículos involuntarios, como las caídas; lo escatológico; lo picaresco, que proporciona una comicidad de engaños, estafas, burlas, etc.; y lo erótico: se puede notar como todas las categorías remitan a una rebeldía contra las convenciones sociales, de lo racional, de la lógica, y de la moral. En este sentido, la comicidad escatológica representa el acto subversivo más radical y trangresivo, que introduce en el mundo social lo que normalmente se excluye porque causa vergüenza (Jammes 1980: 7-9).

${ }^{30}$ Sobre la función propagandista de la comedia en la sociedad del Siglo de Oro véase Díez Borque 1976: 129 y ss. El estudioso subraya también que la función de la comedia era la de proyectar una imagen idealizada del poder, que ofreciera una "evasión de la realidad" (Díez Borque 1976: 357); al teatro del Siglo de Oro, por lo tanto, no se podría atribuir un auténtico valor realistico o testimonial bajo la perspectiva histórico-social.

${ }^{31}$ La obra de Trissino en 1562 se publicó dividida en seis partes, llamadas Divisioni: las cuatro iniciales se dedicaron a cuestiones lingüísticas y métricas, la quinta y la sexta a otros mótivos de las principales polémicas literarias de la época, como mímesis, catarsis, poema y tragedia.

32 Vega 1997: 33 se refiere a esta diferencia fundamental entre tragedia y comedia distinguiendo el sentido de semejanza que supone la tragedia de la que define "desemejanza cómica", que posibilita la reacción de risa.
} 
En el ámbito de la colectividad, la risa por lo tanto representa un gesto social, que castiga y "exorciza" las fealdades que condenan a una existencia marginada, indicando una incapacidad de adaptarse a la sociedad (Nardi 2006: 89). La comicidad se funda en un mecanismo ambiguo, desacralizador de los valores comunes, desvelando lo absurdo de lo que se considera normal y la lógica de esta absurdidad, pero con el objetivo final de confirmar y reforzar estos valores.

La risa, y su concepción en el mundo social, se configura como un acto que existe y se construye entre tensiones diferentes, entre repulsión y aceptación, rebeldía contra el orden y restablecimiento del mismo. En la base de estos conceptos queda siempre el sentido de superioridad que las clases altas y cultas ejercen sobre el pueblo, tanto en el propósito de educarlo, ética, moral y estéticamente, como en la función propagandista de la comedia, que fortalece la imagen de una monarquía sólida y rica, garante del orden social y del bienestar del reino. 


\section{Bibliografía}

Antonucci, Fausta (2011), «Lo cómico y lo trágico mezclado», in Poggi, Giulia; Profeti, Maria Grazia (eds.), Norme per lo spettacolo. Norme per lo spettatore. Firenze: Alinea, 99- 118.

Annotationi = Annotationi / di M. Alessandro / Piccolomini, / nel libro della / Poetica d'Aristotele; / con la tradvttione del / medesimo Libro, in lingua Volgare. / con privilegio / in vinegia, / Presso Giouanni Guarisco, \& Compagni (1575).

Arte nuevo = Vega, Lope de, Arte nuevo de hacer comedias. Rodríguez, Evangelina (ed.). Madrid: Castalia, 2011.

Arte poética $=$ Minturno, Sebastiano Antonio, Arte poética . Bobes Naves, María del Carmen (ed.), Madrid: Arco/Libros, 2009, 2 vols.

Aut. $=$ Real Academia Española, Diccionario de Autoridades. Madrid. Imprenta de Francisco del Hierro, 1726-1739 [http://web.frl.es/DA.html].

Bobes Naves, María del Carmen (2008), "Teoría de la comedia en la Poética toscana de Sebastiano Minturno", Revista de Literatura, vol. 70/ núm. 140: 371-404.

Cartas $=$ Cascales, Francisco, Cartas filológicas. Alicante: Biblioteca Virtual Miguel de Cervantes, 1999. Edición digital a partir de la de Murcia, Luis Verós, 1634 [http://www.cervantesvirtual.com/nd/ark:/59851/ bmc7m057].

Cisne $=$ Carvallo, Luis Alfonso de, Cisne de Apolo. Alberto Porqueras Mayo, Alberto (ed.). Kassel: Reichenberger, 1997.

Conde Parrado, Pedro (2010): «Las paradojas de Lope ante los modelos clásicos», in Pedraza Jiménez, Felipe, González Cañal, Rafael y Mercello, Elena (eds.), El Arte Nuevo de hacer comedias en su contexto europeo (Congreso internacional, Almagro, 28, 29 y 30 de enero de 2009). Cuenca: Ediciones de la Universidad de Castilla-La Mancha, 41-54.

Díez Borque, José María (1976), Sociología de la comedia española del siglo XVII. Madrid: Cátedra.

Discorso $=$ Denores, Giason, Discorso intorno a que' principii, cause et accrescimenti che la comedia, la tragedia et il poema eroico ricevono dalla filosofia morale e civile e da' governatori delle republiche; onde si raccoglie la diffinizione e distinzione della poesia nelle predette tre sue parti e la descrizione particolare di ciascheduna, in Weinberg, Bernard (ed.), Trattati di poetica e retorica del Cinquecento. Bari: Laterza, vol. III, 375-419.

Divisione $=$ Trissino, Giovan Giorgio, Quinta e sesta divisione della Poetica, in Weinberg, Bernard (ed.), Trattati di poetica e retorica del Cinquecento. Bari: Laterza, vol. II, 7-90. 
Ética $=$ Aristóteles, Ética nicomáquea, in Lledí Íñigo, Emilio y Pallí Bonet, Julio (eds.), Ética nicomáquea. Etica eudemia. Madrid: Gredos, 2014, 7-408.

Favola = Del Bene, Giulio, Che la favola della comedia vuole esser onesta e non contenere mali costumi, in Weinberg, Bernard (ed.), Trattati di poetica e retorica del Cinquecento. Bari: Laterza, vol. III, 177-190.

Intorno al comporre = Giraldi Cinthio, Giovan Battista, Discorso intorno al comporre delle comedie et delle tragedie, in Villari, Susanna (ed.), Discorsi intorno al comporre. Messina: Centro interdipartimentale di studi umanistici, 2002, 207-318.

Jammes, Robert (1980), «La risa y su función social en el Siglo de Oro», in Risa y sociedad en el teatro español del Siglo de Oro, Actes du $3^{\mathrm{e}}$ colloque du Groupe d'Etudes Sur le Théâtre Espagnol. Toulouse, 31 janvier - 2 février 1980. Paris: C.N.R.S., 3-11.

Menéndez Pelayo, Marcelino (1974): Historia de las ideas estéticas de España. Madrid: Consejo Superior de Investigaciones Científicas, 2 vols.

Nardi, Florinda (2006), Percorsi e strategie del comico. Comicità e umorismo sulla scena pirandelliana. Roma: Vecchiarelli Editore.

Phil. Ant. Poét. = Pinciano, Alonso López, Philosophía antigua poética . Rico Verdú, José (ed.), Madrid: Biblioteca Castro, 1998.

Plebe, Armando (1952), La teoria del comico: da Aristotele a Plutarco. Torino: Giappichelli.

Poética $=$ Aristóteles, Póetica in Martínez Manzano, Teresa y Rodríguez Duplà, Leonardo (eds.), Poética. Magna moralia. Madrid: Gredos, 2011, 9-100.

Poetica d'Aristotele $=$ Castelvetro, Lodovico, Poetica d'Aristotele volgarizzata et sposta. Muuchen. Fink, 1968. Rist. anast. ed: Vienna: Gaspar Stainhofer, 1570, 2 vols.

Profeti, Maria Grazia (2010), «Me llamen ignorante Italia y Francia», in Pedraza Jiménez, Felipe, González Cañal, Rafael y Mercello, Elena (eds.), El Arte Nuevo de hacer comedias en su contexto europeo (Congreso internacional, Almagro, 28, 29 y 30 de enero de 2009). Cuenca: Ediciones de la Universidad de Castilla-La Mancha, 55-73.

Refini, Eugenio (2009), Per via d'Annotationi. Le glosse inedite di Alessandro Piccolomini all'Ars poetica di Orazio. Lucca: Maria Pacini Fazzi Editore.

Sánchez Laílla, Luis (2000), “Dice Aristóteles»: la reescritura de la Poética en los Siglos de Oro", Criticón, vol. 79: 9-36.

Shepard, Sanford (1970), El Pinciano y las teorías literarias del Siglo de Oro. Madrid: Gredos.

Tablas $=$ Tablas $/$ poeticas, $/$ del licenciado / Francisco Cascales. $/$ Dirigidas al Excelentissimo Señor Don Francisco / de Castro, Conde de Castro, Duque de 
Federica Zoppi

Taurisano, /Virrey, y Capitan general del / Reyno de Sicilia. / con privilegio / En Murcia, Por Luis Beros, Años de / 1617.

Vega, María José (1997), La formación de la teoría de la comedia. Francesco Robortello. Cáceres: Universidad de Extremadura.

Villari, Susanna (2002), «Premessa» in Villari, Susanna (ed.), Discorsi intorno al comporre rivisti dall'autore nell'esemplare ferrarese Cl. I 90. Messina: Centro interdipartimentale di studi umanistici, v-cxxiiii. 